\title{
Assimilation Conundrum: Austrian Befriends Americans in Costa Rica
}

\author{
Michael Craig Budden, (E-mail: mbudden@selu.edu), Southeastern Louisiana University
} Heather Lynn Budden, Southeastern Louisiana University

\begin{abstract}
The number of international students coming to the United States has fallen during the past two years. Still, many come. They seek an education that may be unavailable at home or just an opportunity to study in a foreign environment. Upon graduation, many return home with subject matter knowledge gleaned in the classroom but no real understanding of Americans or America. Those lacking assimilation and acceptance among US students return to their homelands shortchanged and in some ways, less prepared than they should be to deal in a multi-cultural environment. International students need to be assimilated in such a manner as to enrich their understanding of the United States and to broaden their horizons. Too, assimilation may lead to an increase in the numbers of foreign students seeking an education in the U.S. In a similar vein, U.S. students can enrich their knowledge and understanding of foreign cultures through close interaction with foreign students.
\end{abstract}

\section{INTRODUCTION}

ince 1993, the number of international students attending institutions of higher education in the U.S. has been significant. International students represent between $3.1 \%$ and $4.6 \%$ of enrollment in the U.S. (Institute of International Education, 2005). In each of the years 2003/04 and 2004/05, international enrollment in U.S. universities and colleges has declined. In the most recent reporting year, international students comprise $4.0 \%$ of total U.S. enrollment, or 565,039 students. That $4.0 \%$ is down from a high of $4.6 \%$ in the $2002 / 03$ year. It is no surprise to those in academia that after the terror attacks of 2001, the flow of new international students slowed significantly, growing only $0.6 \%$ in the 2002/03 academic year (IEE, 2005), and declining thereafter.

According to Institute of International Education figures (2005), the number of foreign students enrolled in U. S. higher education increased every year from 1954/55 until the precipitous drop of 2003/04. In the two years between 2002/03 and 2004/05, the number of international students in the U.S. declined by 21,284. The tuition dollars lost to university coffers represented by such a decline is significant. Universities across the country are working to improve the flow of communication with international applicants and increase the likelihood that such students will be able to travel to the U.S. to study.

Still, despite the loss of more than 21,000 students, U.S. institutions are still attracting more than one-half million foreign students each year. This represents a sizeable number no matter the trend, and a sizeable impact on university budgets. Hence, foreign students represent a sizeable, valuable group to U.S. higher education institutions. Many of the students who travel to the U.S. come from the more affluent families in their homelands, and can exert influence on others who may wish to come to the U.S. to study. Thus, their experiences, good or bad, will play a role in their reflections and recommendations to others as they consider attending U.S. institutions.

Undeniably, foreign students come to the U.S. for an education. They seek an education that will serve them and their families well. Many will return to their homelands seeking to advance the state of their families, their communities, and ultimately, that of their homeland. Their education will play a major role in their ability to foster economic and social growth abroad. Their education and experience will play a role in their understanding of, and feelings toward, others, especially Americans. The importance of their formal education and its bearing on their being 
productive citizens cannot be overstated. At the same time, their informal education and experiences in the U.S. are important and will bear on their perceptions of America, its people, and its institutions. It is important that foreign students leave the U.S. knowing Americans, and it is important that Americans advance our knowledge of foreign cultures and improve our understanding of global issues through becoming acquainted with these students.

\section{THE STUDY ABROAD PROGRAM}

Our college's study abroad program involves a trip to Costa Rica. Annually, 45 business students visit Costa Rica for 10 days. During that visit, the students are exposed to a variety of business and government leaders, and make twice daily field trips in which they observe first-hand the workings of Costa Rican businesses. While there, they also participate in a variety of cultural enrichment activities including dinners with local specialty foods, native dancing, and museums. Students attend soccer matches and dance clubs in the evenings for recreation and to further taste the local culture. Trips to rain forests, white water rafting excursions, and canopy tours expand student knowledge and horizons considerably. A highlight of the trip is a visit to a national park reserve and beach at the end of the program.

Daily, students eat breakfasts and lunches as a large group. They eat dinners in small groups as they see fit. Since dinner is not provided through the program, food experimentation in a variety of venues is obtained. Even though Costa Rica is a safe environment, students are encouraged to stay in groups and to travel together when outside the confines of the program. The Study Abroad program in Costa Rican business is the single largest study abroad program on our campus, representing about $40 \%$ of the University's study abroad activity.

To assure student safety, students are encouraged to band together and travel with classmates anywhere they go. In addition, students are encouraged to stay in public areas and entertainment facilities that are widely recognized, and not to travel to unknown or potentially dangerous areas.

As for housing, students and faculty stay in the same hotel while in town. At the beach, they stay at the same resort. Students are assigned two or three to a room. The room assignment expectations help control program costs and provides for an immediate and personal grouping that assures that students will know at least one other student on a close and personal basis. It also helps ensure safety as at least two are together in almost all activities.

\section{PROBLEM RECOGNITION}

On one such trip two years ago, three of the 45 students who participated were from foreign countries. A female student from Austria, a male student from Germany and a male from France participated in our Costa Rica study abroad program. During the 10 days in Costa Rica, admittedly an intense 10-day program, students had grown into a cohesive, close-knit group. The 45 participants had done what most of the students participating previously had done: they had bonded into a close knit group that knew each other well, and appreciated each other's company.

Upon returning to the states, the close personal relationships developed during the program continued. Indeed, one month after the trip, the group had a formal "reunion" at a local restaurant. Prior to the reunion, students had emailed their photos to the class "president" who created a CD of all photos. At the reunion, copies of the CD were distributed. Scrapbooks with photos and remembrances were shared and enjoyed. By the time that reunion ended, plans were being made to have a second reunion.

Yes, the program was an educational success. It exposed students to numerous business and government practices that enriched the students and broadened their horizons. It resulted in close-knit relationships that are still strong. Indeed, at least one marriage has grown from our program, and a second engagement is in the works. The program has been a success in many ways. Indeed, in one way we had not envisioned.

At the reunion, the student from Austria made a comment that she had spent a year on campus living in University housing, eating in the University cafeteria, reading in the library, and going to classes, but had failed to really know any Americans. Most of her time on campus and off campus was spent with other foreign students who 
had banded together out of a common feeling of being outsiders and a recognition that there was a separation perceived or real, between American students and foreign students. She said that as a result of her trip to Costa Rica, she finally had come to know, and to love Americans. She had made American friends, something she said she had not done previously. She mentioned that she would return to Austria at the end of the summer with an understanding of Americans that she had failed to grasp in over a year on campus, but had grasped in 10 days in Costa Rica. She was amazed and thankful that she had participated in the study abroad program. She had American friends and felt that she had a new appreciation for life in the United States. Finally, she mentioned that we should encourage all foreign students to participate in the study abroad program, as they will get to know Americans in a close and personal manner, unavailable through the usual academic programs on campus. Since her program of study was only for one year, her experiences and assimilation while on the trip were timely indeed.

In a similar vein, U.S. students had come to know the international students on a close and personal basis. U.S. students had enriched their knowledge of foreign cultures and their understanding of peoples from different backgrounds. Several mentioned they enjoyed the company of the international students and had learned much from them. The hugs "good-bye" both at the airport and at the conclusion of the reunion said it all. American and international students alike enjoyed the program and the ability to meet new and different friends.

The 10-day program's close-knit and inclusive nature had apparently managed to accomplish something that more time on-campus had failed to accomplish - advance personal understanding and respect among U.S business students and international business students. This increase in awareness and respect needs to be replicated and improved. Further efforts and activities aimed at increasing international student assimilation should be developed and encouraged.

\section{RECOMMENDATIONS FOR ASSIMILATION}

Business programs should and can encourage assimilation of international students into their programs. Specifically, several direct efforts can help assimilate international students, indeed all students into the university experience. Specifically, classroom exercises, extra-curricular activities, pragmatic exercises including study-abroad experiences, and housing assignments can all add to the goals one sets for increasing assimilation of foreign students.

The classroom is a great place to start. Through group assignments, professors can work to ensure in-class efforts that provide assimilation of all students. Care should be taken to not allow a situation where all international students end up in a singular, non-assimilated group. By assigning groups that are comprised of both U.S. and international students, assimilation can be encouraged. Ideally, during the course of a term, the professor may require that students form different groups than those of earlier exercises. Again, by rearranging groups over time, maximum exposure of all students with one another will result.

Also, in the classroom, discussions concerning diversity and/or international topics can be designed so that students with international backgrounds can contribute to the discussion on a first-account basis. These students will thus have an opportunity to express themselves and provide a non-American perspective on issues of discussion. These students will also be given an opportunity to speak English in a classroom setting, an exercise that can only improve their ability to communicate in the U.S. but throughout the English speaking world. At the same time, U.S. students in such classes will have further opportunities to explore the intricacies of another culture. As a result, all students will increase their global awareness and improve their chances of developing valuable friendships with international students.

Extra curricular activities are ripe with opportunities to develop awareness and understanding of students from other cultures. While international clubs are not uncommon on campuses, many are heavily populated with international students. Members of organizations that are heavily international in membership may broaden their horizons of foreign cultures, but they will do little to advance an understanding of U.S. students. School officials and faculty sponsors can and should encourage U.S. students to get involved in the international club. Such encouragement can be in the form of credit toward assignments with an international focus. Encouragement may be come in the form of an expectation for those students majoring in international programs or foreign languages. 
Whatever the encouragement, it will advance a goal of assimilation and mutual education. Through such involvement, U.S. students will have ready access to foreign cultures. They will increase their understanding of foreign students and the cultures from which they come. It can truly be a synergistic experience.

Study abroad opportunities like the one described earlier can provide a backdrop for desired assimilation. It is shame when an international student must travel to Costa Rica to make friends with Americans, but it is better than not making friends at all. Essentially, study-abroad excursions can create a cohesive group of students. Since they "are in it together" they must and will become closer. These friendships will enrich the learning experience and make all closer to one another and to the school they attend. Such an affinity with their alma mater can serve well as a catalyst for future alumni endeavors and recruiting activities.

While on the subject of study abroad programs, they can provide a great opportunity for close inter-action and result in assimilation gains. They are great for exposing students to a foreign culture. It should be mentioned that the study-abroad model might be applied to in-country programs with a similar focus. Such a program could further the knowledge of the U.S., among U.S. and foreign-born students and provide a domestic route to improve assimilation. It may also prove more cost effective and attractive to a larger number of students.

Finally, the university itself through its housing assignments can aid the assimilation process. By mixing international students with native-born students, assimilation can be fostered. Too often there is a tendency for international students to ban together, even in housing. This banning-together may result in a close-knit international community but results in a less-than optimal assimilation experience. By assuring international students are housed with Americans, or at least not isolated in housing, they are more likely to get to know and befriend Americans. Many university housing units are arranged in suites. The suite arrangement is ideal for encouraging assimilation while also fostering the feeling of "safety in numbers" among international students. Housing students in a manner that fosters assimilation is just another step that can aid the process of encouraging friendships and ties to the local university community.

\section{CONCLUSIONS}

Students who have positive experiences in college are more likely to progress in their programs. As Pritchard and Wilson (2003) state, many psychological variables impact college GPA and retention. Further, Pritchard and Wilson cite studies that indicate that student social health, in the form of student involvement, is important to success and retention in the first year. They cite that the development of inter-personal relationships has been seen as a critical success factor for student success (Pritchard and Wilson, 2003). After graduation, students with emotional ties that have had positive experiences in college are more likely to be active alums, and they are more likely to provide future support for programs. It is exactly this kind of assimilation that can produce satisfied students - international and domestic. Faculty members need to address the assimilation question and foster a climate where the learning experience is maximized for all students.

\section{REFERENCES}

1. Giegerich, S. (2003, November 3). Increase in foreign students slows. http://www.boston.com/news/nation/articles/2003/11/03/increase in foreign_students_slows. Printed $2 / 8 / 06$.

2. Institute for International Education, Open Doors 2005: Report on international educational exchange. http://opendoors.iienetwork.org/?p=69692. Printed 2/8/06.

3. Pritchard, M. E. and Wilson, G. S. (2003, January/February). Using emotional and social factors to predict student success. Journal of College Student Development, (44) 1, 18-28. 